\title{
Self-management in heart failure: where have we been and where should we go?
}

This article was published in the following Dove Press journal:

Journal of Multidisciplinary Healthcare

31 March 20I I

Number of times this article has been viewed

\author{
Nancy Jean Gardetto* \\ Division of Cardiology, \\ Department of Veterans Affairs, \\ San Diego, CA, USA \\ *Ms Gardetto is also a doctoral \\ student at the Uniformed Services \\ University of the Health Sciences, \\ Bethesda, Maryland, USA
}

Correspondence: Nancy Jean Gardetto MSN, RNP-c

Division of Cardiology,

VA San Diego Healthcare System,

3350 La Jolla Village Drive, Mailstop

II8, San Diego, CA 92161, USA

$\mathrm{Tel}+\mathrm{I}$ 858-642-35I2

Email nancy.gardetto@va.gov

\begin{abstract}
Chronic conditions such as heart failure (HF) place a tremendous strain on patients, their families, the community, and the health care system because there are no real "cures". Adding to the burden are longer life expectancies and increased numbers of people living with multiple chronic conditions. Today, whether engaging in a health-promoting activity, such as exercise, or living with a chronic disease such as HF, the individual is responsible for actively managing day-to-day activities, a concept referred to as self-management. Self-management emerged as the cornerstone for chronic care models and multidisciplinary disease-management strategies in chronic illness care. Moreover, self-management has been prioritized as a central pathway for improving the quality and effectiveness of most chronic HF care. Adherence to selfmanagement is vital to optimize the treatment outcomes in HF patients, but implementing chronic disease self-management (CDSM) strategies and identifying the difficulties in self-management has proved to be a challenge. Understanding both where we have been and the future direction of self-management in HF care is not only timely, but a crucial aspect of improving long-term outcomes for people with HF and other chronic diseases.
\end{abstract}

Keywords: self-management, heart failure, chronic disease, self-care, disease management

\section{Chronic heart failure: a common but serious problem}

Chronic disease is a serious and expensive public health problem worldwide. In chronic illness care, heart failure (HF) is one of the few cardiovascular diagnoses where disease prevalence is rising rather than falling. ${ }^{1,2}$ Owing to a rapidly aging population and improved survival from acute cardiac events, approximately 5.8 million Americans are living with HF, with an estimated incidence of 660,000 new cases each year. ${ }^{1,2}$ In adults, HF has emerged as a common principal Medicare hospital discharge diagnosis, and a leading cause of readmission within 30 days of an HF admission. ${ }^{2,3-6}$ Although patients hospitalized with acute decompensated HF improve during the incident admission, the long-term all-cause mortality rate remains high and has improved little over time despite important therapeutic advances and national quality improvement efforts. ${ }^{2,3}$

Today, whether engaging in a health-promoting activity such as exercise or managing a chronic disease such as HF, the individual is responsible for actively managing day-to-day activities, a concept commonly referred to as self-management. Selfmanagement strategies have become a core component and major theme of many disease management programs and chronic care models at organizational levels. ${ }^{7}$ The clinical trajectory of chronic HF is characterized by chronic symptoms interspersed with acute symptoms, which often result in adverse events and poor outcomes. 
One process for reducing the burden of HF symptoms in the everyday life of those living with chronic HF is to identify effective approaches to chronic illness care, which support successful self-management. ${ }^{8,9}$ Furthermore, to maximize effective behavioral interventions, efforts must focus on understanding the challenges individuals face in managing the complex demands of their illness and the often multiple and competing conditions.

Gaps in our understanding of the characteristics that influence self-management behaviors, and the lack of evidence that self-management translates to better health outcomes in HF patients, suggest a need for further dialog among health care providers and clinicians interested in improving care for people living with chronic HF. The aim of this narrative literature synthesis is to contribute to the evidence base on self-management in HF by describing where we have been, what additional information we may need, and where we need to go with self-management in chronic HF care.

\section{Chronic disease self-management: historical perspectives}

Over the past few decades, the United States (US) has witnessed increasing prevalence of chronic diseases and skyrocketing health care costs. Because of the tremendous clinical and financial impact of chronic illness care, managing chronic disease has become a focal point for health care stakeholders, policy makers, and researchers. Adding to the mounting evidence that chronic illness care is fragmented and poorly coordinated is the criticism that US health care systems provide health care on an episodic, acute care basis, and lack systematic approaches to managing chronic disease. ${ }^{7,8}$ To correct deficiencies in the organization and delivery of chronic care and to reduce the burden of escalating costs, disease management emerged as a comprehensive approach and strategic model for chronic illness care. ${ }^{10}$ Self-management is the catalyst or backbone for many disease management approaches because it is patientcentered, focuses on helping people with chronic disease become more informed about their illnesses, and actively engages patients in their own health care. The Institute of Medicine (IOM) identified self-management as a top priority for US health care. In addition, the Centers for Disease Control and Prevention (CDC) State of Aging and Health in America Report also prioritized self-management, with six of its seven calls-to-action identifying self-management as a central pathway to improving outcomes in people with chronic disease. ${ }^{7,11}$
For this review, chronic disease self-management (CDSM) will be used as an umbrella term to cover the broad diversity of programs, approaches, models, and interventions used to improve the quality of care for people living with chronic disease. Self-management is an essential component of chronic illness care. It is important to highlight that the terms disease management and self-management have been used in a variety of ways in the literature. A major challenge for dissemination of research outcomes for chronic illness care has been the absence of universally accepted definitions for disease management and self-management, or standardization for CDSM programs and strategies. ${ }^{10}$ Despite the encumbrance imposed by the lack of standardization, both private and public interest in CDSM grew, and many of these strategies were adopted on a wider scale by the mid-1990s. Once established, this interest spread rapidly, accompanied by comprehensive initiatives to improve chronic illness care and outcomes while reducing health care expenditures. ${ }^{12}$

In broad terms, CDSM programs are populationbased approaches that engage in collaborative practice using multidisciplinary health care teams with specialized education and training. The widespread attraction of selfmanagement coincided with a period of significant transition within the US health care delivery system from a paternalistic model of acute medical care, whereby patients were passive health care recipients, to one in which patients became active participants in their health care. Over the past two decades, research has concluded that chronic HF care is a staggering and expensive public health problem. US health care systems are under pressure to slow or reverse the often poor outcomes, escalating health care costs, and high utilization rates associated with chronic illness care. ${ }^{8,10,13}$ Adding to this burden are demographic projections that suggest dramatic increases in chronic illness care and resource utilization. This concern led to recommendations from policy makers for further research to identify optimal CDSM programs, to change patient behaviors, and to improve the health of the chronically ill. ${ }^{14}$

\section{Self-management in heart failure: where have we been?}

As with other chronic conditions, the major goals of CDSM in $\mathrm{HF}$ are to reduce symptoms and medical care costs while improving clinical outcomes. The interchangeable use of the terms self-care and self-management and the struggle to reach consensus or a gold standard definition has imposed limitations on understanding and promoting self-management in chronic HF care. To remain consistent with national goals 
advocated by the IOM, the CDC, the Agency for Healthcare Research and Quality (AHRQ), and the acronym CDSM, the term self-management will be used. Self-management is derived from definitions set out by Lorig and Holman ${ }^{15}$ and Barlow et $\mathrm{al}^{16}$ based on the individual's ability (problem solving, decision making, resource utilization, formation of patient-provider partnerships, action planning, and tailoring of daily activities) to undertake and manage day-to-day tasks, inherent lifestyle changes, physical symptoms, and psychosocial consequences of health and well-being over the lifetime of an illness. Throughout the remainder of this review, self-management will be considered as interchangeable with the terms self-care or self-care behaviors.

Despite differences over terminology and definitions and their conceptualization in the HF literature, there is wide acceptance of the American Heart Association's (AHA) recommended behaviors for persons living with HF (medication adherence, symptom management, dietary adherence, exercise, smoking cessation, and preventative behaviors). ${ }^{17} \mathrm{HF}$ patients are strongly encouraged by clinicians to regularly take medications, monitor their condition and symptoms, keep appointments, and contact their health care providers when needed. ${ }^{17}$ Strategies such as monitoring weight, remembering to take medications daily and on time, and following a low-salt diet are among the core recommendations in HF guidelines and have been shown to be beneficial for HF patients. ${ }^{1,17}$ Regardless of how seemingly simple these recommendations may appear, making plans to adhere to, and apply, the prescribed behavior changes in daily activities requires decision making and problem solving skills for self-management. ${ }^{17}$ With or without the help of family members or caregivers, it is the patient's responsibility to integrate the vast majority of $\mathrm{HF}$ care into his or her daily life. ${ }^{17}$

The challenges associated with managing HF and adhering to self-management are proving to be difficult problems for health-care providers, policy makers, and patients. First, HF is a complex disease that requires substantial resources for chronic medical management; despite significant advances in $\mathrm{HF}$ therapies, hospital readmission rates in HF patients remain high. Secondly, because it is difficult for clinicians to keep abreast of the latest recommendations and research findings, adherence to published guidelines and life saving therapies remains less than ideal. ${ }^{18}$ Many people living with HF are elderly, are symptomatic, lack social and financial support, and have more than one comorbid condition, making their HF care and management complicated. ${ }^{19}$ Finally, research on specific behaviors or characteristics of patients with HF is scarce. Further insight into the answers or reasons for the lack of patient adherence, or the ability to identify potential barriers to self-management for risk-stratification in $\mathrm{HF}$ patients is greatly needed. ${ }^{20}$

HF places a tremendous strain on the patient, family members, community, and health care system because there is no "silver bullet" or "cure". Adding to this burden are longer life expectancies and increasing numbers of people with HF living with other conditions. Common comorbid conditions among Medicare-aged beneficiaries with HF include hypertension, diabetes mellitus, dyslipidemia, chronic lung disease, renal dysfunction, cognitive impairment, and osteoarthritis/osteoporosis. ${ }^{21,22}$ In recognition of the complexity of the problem and the substantial demand for health care resources associated with chronic HF care, the AHA, the IOM, the American College of Cardiology (ACC), the Joint Commission on Accreditation of Hospital Organizations (TJC), and the Centers for Medicare and Medicaid Services (CMS) established key quality HF indicators and national goals to standardize hospital-level performance and reduce the high rates of hospital readmission and cost associated with poor clinical outcomes as a focus area for quality improvement efforts. $1,6,7,23$

Research studies confirm that chronic HF can be extremely debilitating, with symptomatic exacerbations that often lead to episodes of acute decompensation, frequent hospital admissions, and premature death. ${ }^{3-6}$ Patient HF hospitalization and rehospitalization rates have attracted considerable attention from policymakers as an indicator of the quality and effectiveness of HF care. Public efforts to improve the use of evidence-based therapeutic approaches and clinical outcomes have focused on hospital-level performance as a core measure of the quality of HF care and a key strategy for reducing subsequent poor outcomes, most notably hospital readmission rates. ${ }^{5,6,23,24}$

Included in these efforts is the implementation of a number of large national HF registries, such as the Acute Decompensated Heart Failure National Registry (ADHERE ${ }^{\mathrm{TM}}$ ), the Organized Program to Initiate Lifesaving Treatment in Hospitalized Patients with Heart Failure (OPTIMIZE-HF), and the Initiation Management Pre-discharge of Carvedilol Heart Failure (IMPACT-HF). These registries aim to collect observational data that will help describe characteristics, management, and outcomes in a broad sample of patients hospitalized for $\mathrm{HF}^{25-27}$

Early observations from registry data document variability in hospital-level performance, delays in diagnosis and initiation of HF therapies, and under-use of evidenced-based HF 
guidelines along with high event rates (death or readmission) at hospital discharge in this subset of HF patients. ${ }^{25,27}$ General characteristics and select outcomes of Medicare beneficiaries enrolled in registries appear similar to the broader, nonregistry Medicare HF population, suggesting that ongoing registry work will provide a valuable resource and insight into clinical characteristics and patterns of care to guide treatment strategies for hospitalized HF patients. However, event rates remain high in this population, a signal that additional work is needed to identify the root cause for HF hospitalizations in order to improve long-term clinical outcomes. ${ }^{3,27-29}$

In a systematic review of literature examining $\mathrm{HF}$ readmission rates, Ross and colleagues ${ }^{6}$ concluded that $\mathrm{HF}$ patient hospitalizations are useful as a clinical marker for disease progression and have value as a means of understanding limited patient and health care system capacity as well as missed opportunities to better coordinate HF care. The authors concluded that the evidence supporting HF hospitalization or readmission as a quality indicator of HF care and outcomes is insufficient. Jha et $\mathrm{al}^{30}$ examined national performance data on hospital discharge planning and associated rates of rehospitalization in HF patients and concluded that current efforts (including public reporting on hospital performance) are unlikely to yield large reductions in unnecessary HF patient hospital admissions. Trends in the hospitalized HF Medicare population have shown some promise, with incremental survival benefits, only minor fluctuations in cost, and isolated reductions in hospital readmission rates; however, nearly $25 \%$ of HF patients are readmitted to the hospital within 30 days of their hospital discharge, an indication that more work needs to be done to change clinical practice and chronic care delivery for this high-risk population to improve their long-term outcomes. . $^{1,2,6,18,23,31}$

Experts recognize that persons living with HF may influence their own health through effective self-management, and poor outcomes have been attributed to insufficient and ineffective self-management. ${ }^{3,9,18,23}$ For those interested in improving outcomes for people living with HF, an important first step requires a better understanding of what makes selfmanagement in chronic HF care so difficult. A major challenge for those living with chronic HF is the "polypharmacy" problem (both pharmacologic and nonpharmacologic interventions) resulting from evidence-based care, dietary restrictions, lifestyle modifications, and ongoing need for frequent contact and medical care follow-up. ${ }^{32}$ Adherence to complex medical regimens, along with the competing demands of daily life and, in particular, multiple chronic conditions, can become overwhelming. It is no surprise that suboptimal adherence to HF self-management has been reported as a major contributor to HF exacerbations that frequently lead to hospitalization and readmission in this population. $^{19}$

Moser et $\mathrm{al}^{33}$ studied the prevalence of risk factors for rehospitalization in 202 recently discharged HF patients, examining risk factors of functional and symptom status, comorbidity, living situation, anxiety, depression, quality of life (QOL), and adherence (medications, low-salt diet, and symptom monitoring). Results showed substantially impaired QOL and high symptom burden, and significant impaired functional status (70\% NYHA III), with 48\% having more than 2 comorbid conditions, $50 \%$ having high levels of anxiety, and $69 \%$ having depression. ${ }^{33}$ The authors concluded that newly discharged HF patients exhibit psychosocial and behavioral risk for rehospitalization.

Evidence shows that poor adherence to prescribed treatments (eg, low salt diet and medications) is a risk factor that can trigger an HF hospitalization or readmission. Lemon et $\mathrm{al}^{34}$ analyzed repeated cross-sectional probability sample surveys using data from National Health and Nutrition Examination Surveys (NHANES) from 1999 to 2006 and reported poor quality diets in persons with HF. Characteristics associated with high sodium diets included male gender, lower education, low economic status, and no reported diagnosis of hypertension. ${ }^{34}$ Ambardeckar and colleagues ${ }^{35}$ investigated a cohort of hospitalized patients to evaluate characteristics and in-hospital outcomes for nonadherent (with diet and/or medications) HF patients. Ambardeckar and colleagues ${ }^{35}$ confirmed that nonadherence with diet and/or medications were identified causes for HF admissions. Common patient characteristics identified by the authors included lower income, younger ( $<65$ years) patients, uninsured, and ethnic minorities. Clinical characteristics identified by the researchers included higher risk HF profiles (lower ejection fraction/worse cardiac function) and symptom severity (evidence of higher volume overload and more symptoms). ${ }^{35}$

Understanding select patient characteristics that influence self-management is critical to providing a coordinated system of chronic HF care. In a Model of Self-Care in Chronic Illness (MSCCI), Connelly ${ }^{36}$ identified 7 variables (age, gender, income, education, social support, symptom severity, and comorbidity) that influence effective self-management in patients with chronic disease. A more comprehensive literature review than set out in the present paper shows that a number of descriptive studies replicating the $\mathrm{MSCCI}^{36}$ model in $\mathrm{HF}$ patients have found contradictory results on which specific characteristics (eg, age, gender) influence self-management in 
HF patients. Many of these studies identified age, functional status, comorbidity, emotional, and economical status as common characteristics that affect self-management behaviors and HF outcomes in the populations' studied. ${ }^{37-44}$ Research that examined potential predictors and characteristics of self-management in HF patients are described below and summarized in Table 1. Although not exhaustive, this list represents a cross-section of original research focused on self-management in HF published in the last 10 years. Experts highlight the dynamic relationship between individual patient characteristics and self-management behaviors and recommend further research in this area. ${ }^{38}$

Artinian and his colleagues ${ }^{39}$ examined relationships between select characteristics (personal and environmental factors) and self-management behaviors in a sample of 110 HF patients. Although no statistically significant relationships were found between select characteristics and total self-care scores, the researchers concluded that certain trends they observed influenced individual self-management behaviors. ${ }^{39}$ Older age positively influenced medication taking, keeping appointments, and receiving a flu shot. HF patients who lived alone were less likely to ask for help during shortness of breath (SOB) and less likely to contact the doctor when they noticed symptoms. Low-income patients living alone were more likely to eat canned or packaged foods, and individuals reporting poor health were more apt to rest, limit activities, ask for help, and contact their doctor regarding symptoms.

Cameron and colleagues ${ }^{19}$ found that 4 of the 7 hypothesized variables taken from the MSCCI model contributed significantly $(P<0.05)$ to variance in HF self-management: male gender, moderate-to-severe comorbidity, depression, and confidence. In a nonexperimental replication study, Chriss and colleagues ${ }^{37}$ found that increased age, male gender, and fewer comorbid conditions contributed to better HF self-management. In a similar study, Rockwell and Riegel ${ }^{38}$ replicated the MSCCI model of 7 characteristics, using data collected from $209 \mathrm{HF}$ subjects participating in a community outpatient CDSM program. Educational level and symptom severity were identified as predictors of HF self-management, explaining $10.3 \%$ of the variance. The authors concluded that those with higher educational attainment and greater symptom severity were more likely to be knowledgeable about the importance of HF symptoms. ${ }^{38}$

Many people living with HF are elderly and symptomatic, lack social and financial support, and have more than one comorbid condition. ${ }^{19}$ Therefore, implementing effective self-management strategies will require understanding the interplay between select patient characteristics and self- management behaviors to identify those in greatest need of CDSM support. ${ }^{19}$ To better understand the manner in which life situations facilitate or impede HF self-management, Riegel and Carlson ${ }^{40}$ conducted structured interviews with 26 HF patients, during which patients described the impact of HF on their daily living experiences and self-management behaviors. The researchers concluded that physical limitations, debilitating symptoms, difficulties coping with treatment, lack of knowledge, distressed emotions, multiple comorbid conditions, personal struggles, and poor family support were common characteristics that contributed to poor self-management in this small sample of HF patients. ${ }^{40}$

A limited number of studies have shown that mastering HF self-management is challenging and that few patients develop sufficient expertise to avoid repeated hospitalizations. ${ }^{41}$ Cameron et $\mathrm{al}^{42}$ examined 143 elderly hospitalized HF patients and described differences in self-management skills between the novice patient ( $<2$ months of HF symptoms) and experienced patient ( $>2$ months of HF symptoms). The authors concluded that experience was a determinant of self-management skills, but experience did not predict the patient's confidence to engage in self-management. Riegel et $\mathrm{al}^{41}$ conducted a qualitative study in 29 chronic $\mathrm{HF}$ patients using in-person interviews and questionnaires measuring characteristics anticipated to influence self-care. The investigator found that only $10 \%$ of the sample were expert in HF self-management, and less daytime sleepiness and more family support distinguished good-vs-expert selfmanagers. ${ }^{41}$ The researchers concluded that less daytime sleepiness and more family support contributed to better self-management. ${ }^{41}$ According to the investigators, the results of this study support prior research findings showing that self-management in persons with HF is poor, but the fact that only 1 in $10 \mathrm{HF}$ patients can be expected to master self-management illustrates the need for further research in this area. ${ }^{41}$

Emerging directions in health care policy have transformed the patient's role from a passive recipient to an active consumer and an engaged member of the health care team. ${ }^{8}$ This approach puts the patient in a key role to influence health care quality and cost. ${ }^{45}$ Critical to achieving the desired outcomes is the active participation of an informed patient. ${ }^{45}$

In our current health care environments, people are being encouraged to take a more active role in self-managing their own health; the rationale for this approach includes the fact that much of the self-management takes place in the individual's everyday life. Research indicates that people who actively self-manage their own care receive higher quality health care 


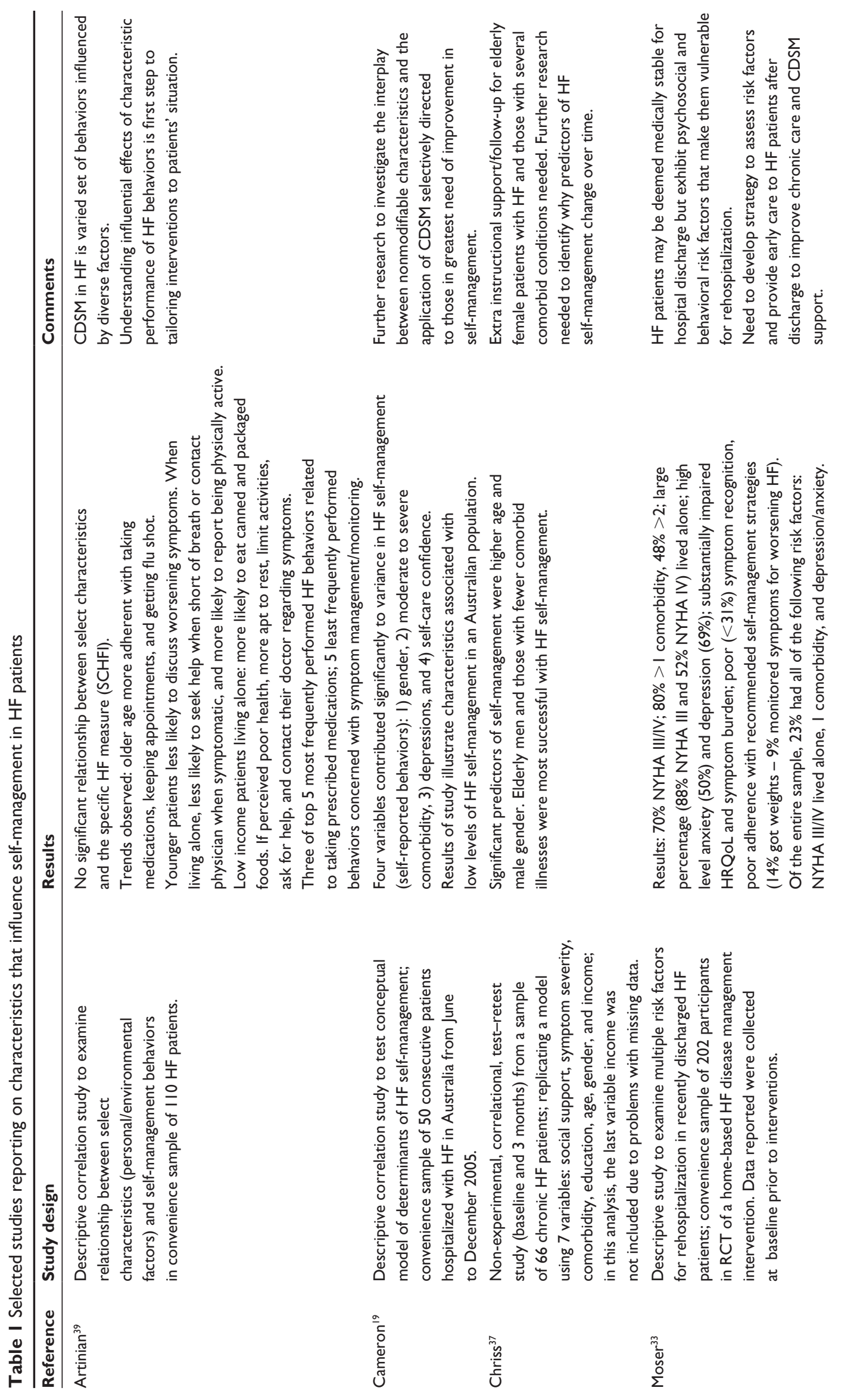




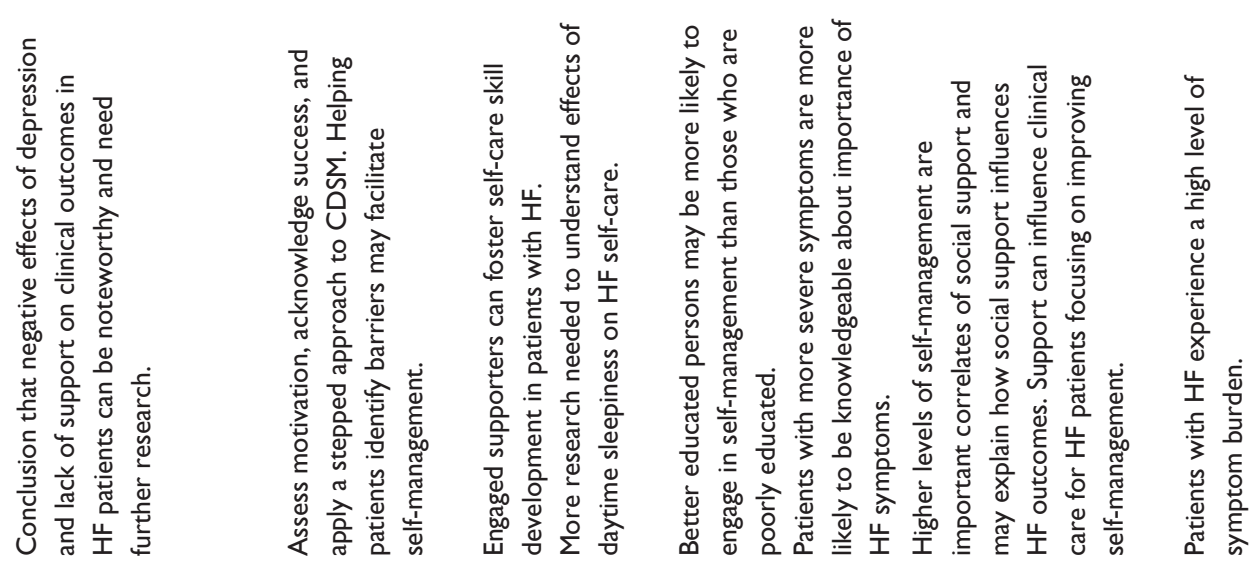
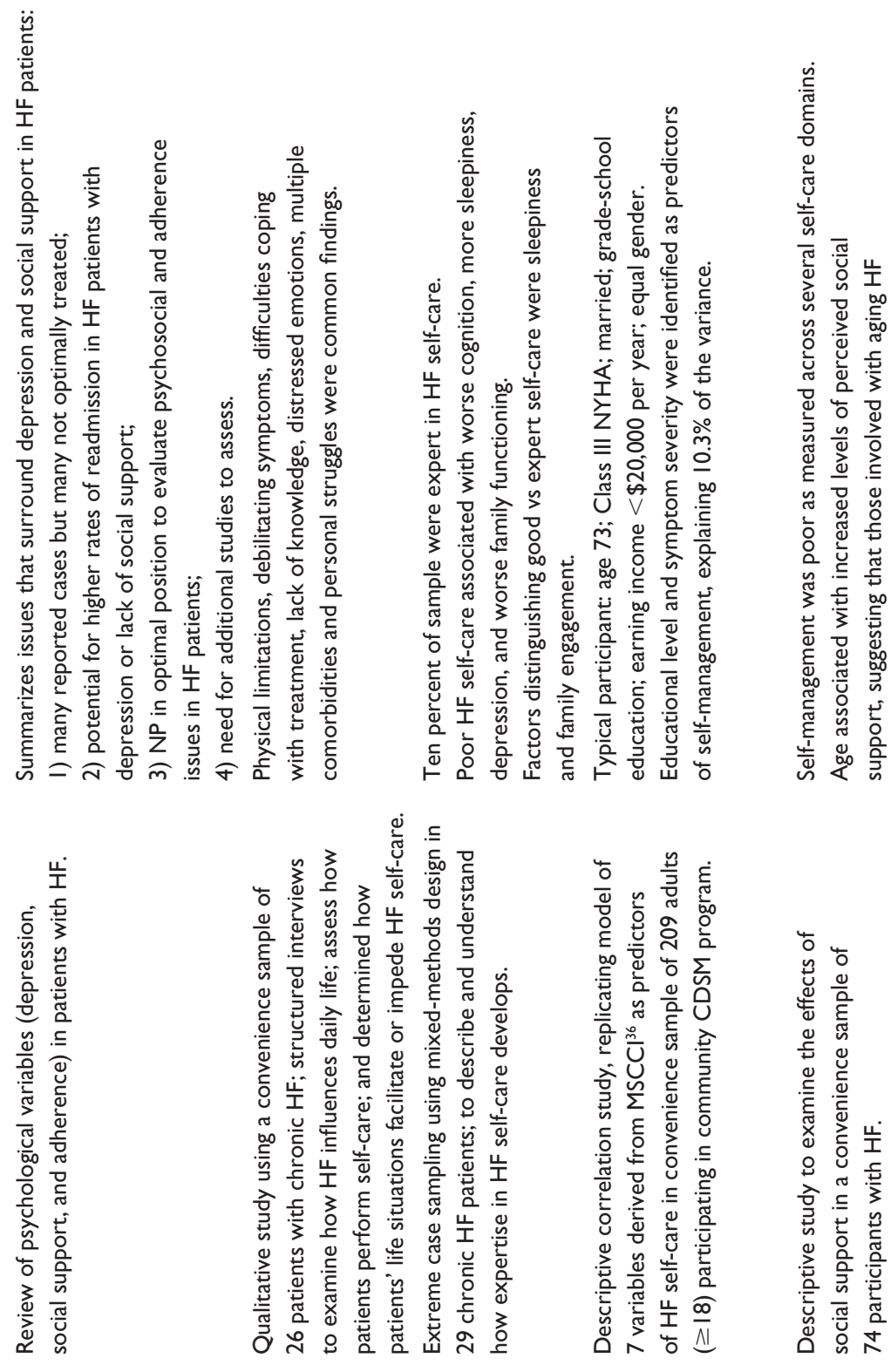

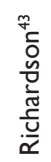
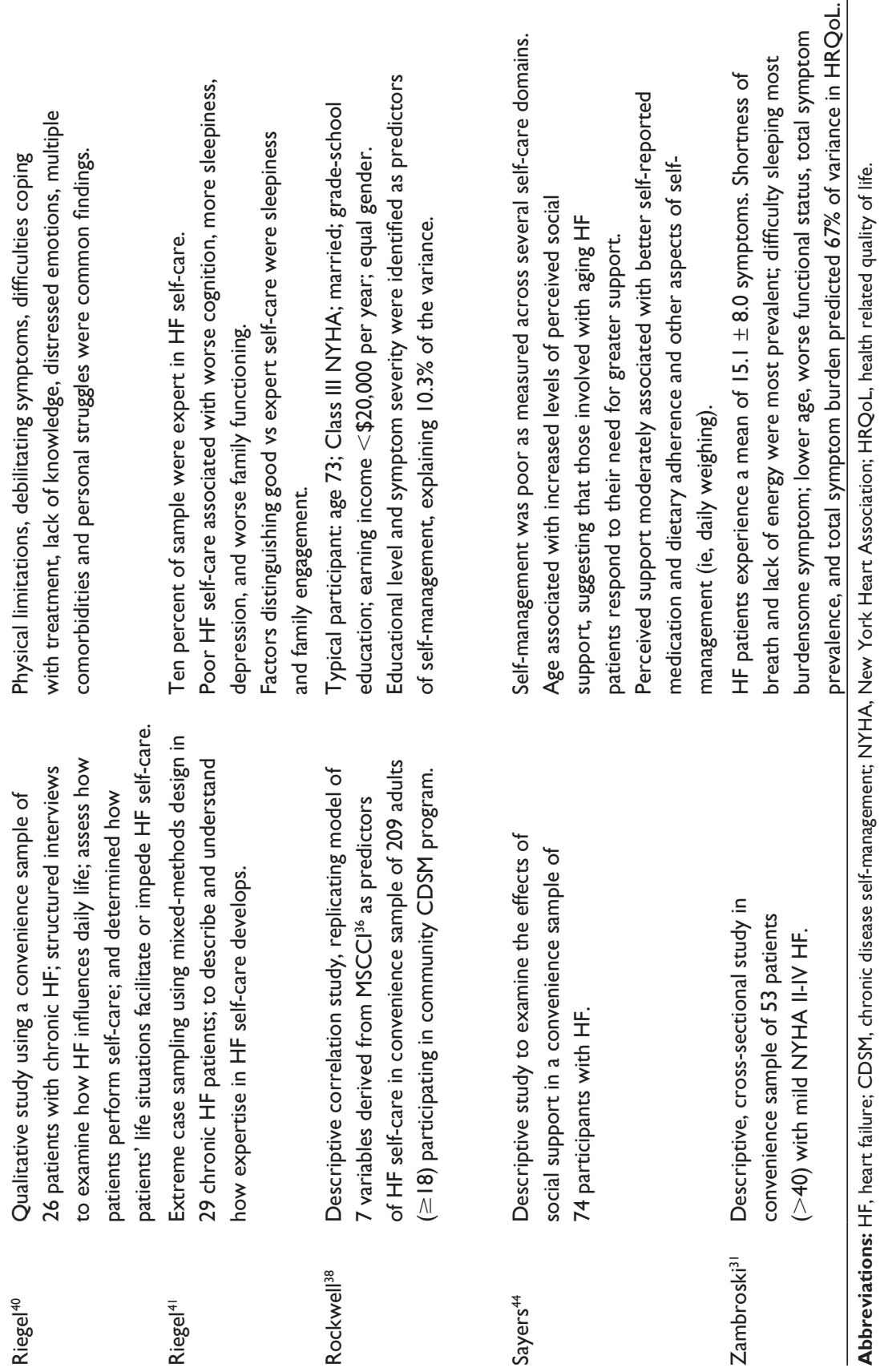
and have better health care outcomes. ${ }^{46-48}$ Central to both consumer-driven health care systems and the chronic illness care model is an engaged and active patient as a member of the health care process. ${ }^{8,45}$ Hibbard and her colleagues from the University of Oregon have described the theory and measurement of consumer and patient activation. ${ }^{45,48,49}$ The degree to which an individual understands the necessity of taking an active role in managing personal health and health care, and feels capable of self-management is described as patient or consumer activation. ${ }^{49}$ More specifically, the term activation is defined by Hibbard, and colleagues ${ }^{45}$ as having the information, motivation, and behavioral skills necessary to self-manage chronic illness, collaborate with health care providers, maintain functioning, and access appropriate care.

The theory of activation and its measurement using the Patient Activation Measure (PAM) have been widely disseminated; PAM has acceptable psychometric properties, as noted by the authors, in patients with chronic illness, and consumers. ${ }^{45,50}$ Table 2 summarizes selected research studies that examine predictive relationships between activation using the PAM (scores) and health outcomes in people with chronic disease. In a controlled trial of 479 chronicdisease patients randomized to either a CDSM intervention or usual care control, Hibbard et $\mathrm{al}^{51}$ showed that changes in participants' levels of activation were accompanied by changes in select self-management behaviors. Individuals with higher activation levels were more likely to engage in health behaviors, such as exercise and following a low fat diet. They are also more likely to engage in disease-specific self-management behaviors, such as taking medications, obtaining preventive care, and requesting and using health information. ${ }^{51}$ Hibbard et a ${ }^{51}$ conclude that if activation, as measured by the self-reported PAM score, was increased, a change in self-management behavior followed.

Mosen et $\mathrm{al}^{52}$ in a study of 4108 adults with chronic conditions, found that patients with high PAM scores were significantly more likely to perform self-management behaviors, use self-management services, and report better medication adherence, compared with patients with low PAM scores. The authors concluded that patient activation is predictive of health outcomes and health care utilization. ${ }^{52}$ Dixon et $\mathrm{al}^{53}$ extended this work using face-to-face semistructured interviews in a convenience sample of 27 adults with at least one chronic condition. Results showed that those low in activation tended to see successful self-management as compliance, whereas the more activated patients (high PAM scores) saw it as being in control and working in partnerships with health care professionals. Both high and low activated patients could be derailed by stress. Barriers in self-management identified by the researchers in people with lower activation included a lack of confidence and knowledge about their condition and fewer strategies for coping with their chronic condition and stress. ${ }^{53}$

According to Hibbard et al, ${ }^{45}$ a valid and reliable instrument to measure activation is necessary, to understand patient activation and its role in health care quality and outcomes in chronic illness care. Most CDSM approaches seek to engage patients to self-manage their own care, but finding effective ways to engage the patient and provide the necessary support has been challenging. Few experimental studies have examined whether chronic HF outcomes can be improved by increasing patient engagement, described by Hibbard et $\mathrm{a}^{45}$ as activation in care and capability for self-management.

\section{Self-management in heart failure: future directions}

The science of self-management in HF care is still young and there is limited empirical evidence of characteristics that predict self-management behaviors or describe the relationship between HF self-management and health outcomes. ${ }^{17}$ Efforts to improve chronic HF care have concentrated on physiologic and clinical variables, hospital and provider performance, and public reporting on quality HF indicators to identify and characterize patient risk. There has been, to date, far less emphasis on patient-centered characteristics as a means of improving chronic HF care.

Persistence of high event rates for death or readmission in people with HF indicate that there is substantial room to improve outcomes that might be achieved through enhancing the quality of outpatient HF care and identifying strategies to stratify patient risk. ${ }^{6,23,31}$ In addition, these high event rates underscore the need for innovative management strategies that will coordinate the transition of patient care from the acute hospital environment to outpatient settings. ${ }^{54-56}$ Emerging directions in health care policy have focused attention on discharge failures and negative outcomes in chronic HF care, making it imperative that health care stakeholders translate evidence-based research into practice.

The Transitional Care Model (TCM) is an evidence-based model of care designed to assist elderly adults with chronic illnesses such as HF to transition from acute care settings into the home or other less intensive health care environments. The TCM has been rigorously tested and refined by a team of researchers at the University of Pennsylvania in both academic 
Table 2 Selected studies reporting on predictive relationships between activation using the Patient Activation Measure (PAM) and health outcomes in chronic care

\begin{tabular}{|c|c|c|c|}
\hline Reference & Study design & Results & Comments \\
\hline Hibbard ${ }^{45}$ & $\begin{array}{l}\text { Convergence of findings from } \\
\text { national expert consensus panel and } \\
\text { patient focus groups to define } \\
\text { concept/id domains of activation. } \\
\text { Operationalize construct } \\
\text { using large item pool, pilot testing, } \\
\text { and initial psychometric analysis } \\
\text { using Rasch methodology. } \\
\text { National probability sample } \\
(\mathrm{N}=15 \mathrm{I5}) \text { with or without } \\
\text { chronic conditions. }\end{array}$ & $\begin{array}{l}\text { PAM is a valid, highly reliable, unidimensional, } \\
\text { probabilistic Guttman-like scale that reflects a } \\
\text { developmental model of activation. } \\
\text { Original research to delineate the process used } \\
\text { to develop a measure for assessing activation } \\
\text { and the psychometric properties of that measure. } \\
\text { Four stages: I) Belief that patient role is important. } \\
\text { 2) Have the confidence and knowledge to take action. } \\
\text { 3) Able to take action to maintain and improve health. } \\
\text { 4) Able to stay the course under stress. }\end{array}$ & $\begin{array}{l}\text { Good psychometric properties } \\
\text { indicating PAM measure can be } \\
\text { used at individual patient level to } \\
\text { tailor interventions and to assess } \\
\text { changes. }\end{array}$ \\
\hline Hibbard ${ }^{50}$ & $\begin{array}{l}\text { Reduce the number of items in the } \\
\text { 22-item PAM while maintaining } \\
\text { adequate precision. }\end{array}$ & $\begin{array}{l}\text { Analysis used the same data collected in the } 2003 \text { via } \\
\text { a telephone survey of } 1515 \text { randomly selected adults. } \\
\text { A I3-item survey scale with psychometric properties } \\
\text { similar to original } 22 \text {-item version. Scores for } 13 \text {-item } \\
\text { measure range in value from } 38.6 \text { to } 53.0 \text { (on a } \\
\text { theoretical } 0 \text { - to } 100 \text {-point scale). Range of values } \\
\text { unchanged from original } 22 \text {-item version. }\end{array}$ & $\begin{array}{l}\text { Results of analysis indicate that } \\
\text { shortened I } 3 \text {-item version is } \\
\text { reliable and valid. }\end{array}$ \\
\hline Hibbard ${ }^{51}$ & $\begin{array}{l}\text { RCT with } 479 \text { chronic disease } \\
\text { patients. Patients randomized either } \\
\text { intervention (Lorig's CDSM program } \\
\text { vs usual care). } \\
\text { Survey data collected at baseline, } \\
6 \text { weeks, and } 6 \text { months. }\end{array}$ & $\begin{array}{l}\text { Significant time effect reported. Activation } \\
\text { increased over time for both groups; intervention } \\
\text { group had significantly higher scores at } 6 \text { weeks but } \\
\text { not at } 6 \text { months. } \\
\text { Positive change in activation is related to positive } \\
\text { change in a variety of self-management behaviors. } \\
\text { This is true even when behavior in question was } \\
\text { not being performed at baseline; increase in } \\
\text { activation is related to maintaining higher level of } \\
\text { behavior over time. Impact of intervention, however, } \\
\text { was less clear, as increase in activation in intervention } \\
\text { group was matched by nearly equal increases in } \\
\text { control group. } \\
\text { Participants who were depressed were less likely to } \\
\text { increase activation or improve self-management } \\
\text { behaviors. }\end{array}$ & $\begin{array}{l}\text { Results suggest that if activation is } \\
\text { increased, improved behaviors will } \\
\text { follow. Question remains: what } \\
\text { interventions will improve } \\
\text { activation? }\end{array}$ \\
\hline Mosen $^{52}$ & $\begin{array}{l}\text { A } 2004 \text { cross-sectional survey of } \\
\text { Kaiser Permanente (KP) medical care } \\
\text { program } N=4108 \text {. } \\
\text { Members with I of } 6 \text { chronic } \\
\text { conditions, including HF, were } \\
\text { included. The sample was selected } \\
\text { from } 7 \text { of KP's } 8 \text { regions. }\end{array}$ & $\begin{array}{l}\mathrm{N}=4108 \text { (6I.2\%) response rate. Used the } 22 \text {-item } \\
\text { PAM and other instruments/measures. } \\
\text { Activation independently associated with } \\
\text { likelihood of performing more self-management } \\
\text { behaviors, using more services, and reporting higher } \\
\text { medication adherence. } \\
\text { First study to find independent association between } \\
\text { activation and health-related outcome measures; } \\
\text { correlation between higher PAM scores and report of } \\
\text { higher satisfaction, higher QOL, and higher physical } \\
\text { and mental functional status scores, compared to } \\
\text { those with lower PAM scores. }\end{array}$ & $\begin{array}{l}\text { Further research is needed } \\
\text { to examine the association } \\
\text { of PAM with prospective changes } \\
\text { in disease specific } \mathrm{QOL} \text { and } \\
\text { utilization measures; impact } \\
\text { of incremental changes in } \\
\text { PAM scores on key outcomes. }\end{array}$ \\
\hline Hibbard ${ }^{49}$ & $\begin{array}{l}\text { Cross-sectional, survey; } 843 \\
(61 \% \text { - relative risk) adults } 25-75 \text { yrs; } \\
\text { used PAM scores to predict positive } \\
\text { and negative emotions; examine } \\
\text { relationship between emotion and } \\
\text { activation level. }\end{array}$ & $\begin{array}{l}\text { Activation level related to average number of positive } \\
\text { and negative emotions: level I, experience almost equal } \\
\text { amounts of }+ \text { /- emotions; higher activation }>\text { greater } \\
\text { number of + emotions; activation score is significant } \\
\text { determinant of emotions, even after controlling } \\
\text { for other factors; PAM level I - feeling } \\
\text { of being overwhelmed; PAM level } 4 \text { - significantly } \\
\text { more likely to have specific health goals than } \\
\text { those at lower levels. }\end{array}$ & $\begin{array}{l}\text { Activation is a measure of } \\
\text { self-management self-concept. }\end{array}$ \\
\hline
\end{tabular}

(Continued) 
Table 2 (Continued)

\begin{tabular}{|c|c|c|c|}
\hline Reference & Study design & Results & Comments \\
\hline $\operatorname{Dixon}^{53}$ & $\begin{array}{l}\text { Qualitative study using semi-structured } \\
\text { interviews with stratified convenience } \\
\text { sample of } 27 \text { people with at least one } \\
\text { chronic illness; to describe how people } \\
\text { with chronic conditions understand } \\
\text { successful self-management, and to } \\
\text { explore barriers to self-management } \\
\text { and strategies employed to manage } \\
\text { chronic conditions and cope } \\
\text { with stress. }\end{array}$ & $\begin{array}{l}\text { People lower in activation tended to see successful } \\
\text { self-management as compliance, whereas those at } \\
\text { higher activation levels saw it as being in control. } \\
\text { Lower activators indicated lack of knowledge and } \\
\text { confidence as barriers to self-management. Both high } \\
\text { and low activated people could be derailed by stress. }\end{array}$ & $\begin{array}{l}\text { Aspects of CDSM support may } \\
\text { need to be tailored to people at } \\
\text { various levels of activation (PAM } \\
\text { scores) to ensure that differences } \\
\text { in understanding, knowledge, } \\
\text { and confidence are addressed } \\
\text { adequately. } \\
\text { More research in this area is } \\
\text { needed. }\end{array}$ \\
\hline
\end{tabular}

Abbreviation: CDSM, chronic disease self-management.

and community settings. ${ }^{57,58}$ Its core components include both in-person contact and a nurse-led, interdisciplinary team approach to increase self-management and improve patient outcomes. ${ }^{57}$ Current efforts are underway to bring TCM into mainstream clinical practice. ${ }^{59}$

Health care reform in the US has focused national improvement efforts in chronic HF care, on reducing 30-day all-cause readmission rates among patients discharged with HF or acute myocardial infarction by $20 \%$ nationally by December 2012. Reducing avoidable hospital readmissions in these patients presents an opportunity not only to improve quality chronic illness care, but also to reduce cost and prevent the loss of Medicare reimbursement for HF readmissions. The Hospital to Home (H2H) national quality improvement initiative, led by the American College of Cardiology (ACC) and the Institute for Healthcare Improvement (IHI), is one strategy that is currently underway to improve the transition from acute inpatient care to outpatient care for chronic $\mathrm{HF}^{60}$ Performance improvement efforts emphasize key areas such as medication reconciliation, early discharge follow up, and symptom management. In clinical practice both the TCM and $\mathrm{H} 2 \mathrm{H}$ models of care coordination are emerging into mainstream use. (Links to the $\mathrm{H} 2 \mathrm{H}$ and TCM websites can be found in the references. ${ }^{59,60}$ ). Although both models of care coordination have been tested and show promising effects in improving desired outcomes and lowering costs for the high-risk chronically ill patient populations, research should examine the contributions of self-management strategies toward achieving these goals. Future efforts focused on the dissemination and the evaluation of program outcomes for HF patients, are greatly needed.

Research has shown that effective CDSM approaches can play a significant role in optimizing HF outcomes and that self-management is central to most chronic HF care. ${ }^{10,61-64}$ While the specific structure, goals, and dimensions of CDSM programs for HF patients vary significantly, most "comprehensive" HF programs include a) practice redesign (use of an integrated multidisciplinary team to provide continuous, coordinated care to patients); b) patient education and support (knowledge, self-management, and behavioral change strategies); and c) clinical expertise (teams typically led by nurse specialists with expertise in HF management). ${ }^{8,17}$ Evidence surrounding HF selfmanagement has focused on delivering an intervention for a set period of time and intensity in varied populations and on describing measurable outcomes based on the specific aim of the research. Results of many of these studies illustrate diversity among characteristics and risk factors associated with poor self-management for HF, and highlight potential barriers and challenges that may contribute to problems with adherence in HF patients. ${ }^{19,39,40}$ Future recommendations for CDSM research and practice include a) developing strategies to aggressively address barriers and risk factors; ${ }^{33}$ b) implementing approaches to effective assessment of self-management deficits so that educational and behavioral strategies can be tailored to individual needs; ${ }^{42} \mathrm{c}$ ) identifying the modifiable and nonmodifiable behaviors and risk factor(s) and selectively directing self-management strategies toward the most modifiable behavior or risk factor(s) that will net the greatest improvement, ${ }^{19}$ and d) improving prerequisite knowledge of self-management and the characteristics of target populations before designing CDSM programs. ${ }^{39}$

Although, CDSM programs share core strategies (eg, multidisciplinary teams, coordination of care, patient education and support, clinical expertise), the individual program components, targeted outcomes, methods of evaluation, and measurement are highly variable and contribute to both challenges and limitations when comparing and contrasting effectiveness and outcomes. ${ }^{10}$ Widespread adoption of CDSM programs have been plagued by methodological shortcomings, limiting the validation of their effectiveness and clinical application. ${ }^{61,65}$ Future efforts 
must include uniform comparison, both within and across conditions (eg, programs and interventions) in order to identify effective program components, populations and settings, and provide sufficient details of program design and methodology to allow for easy replication for the greatest success. ${ }^{65,66}$ Sorting out the most advantageous approaches to better self-management in HF patients is essential to improve chronic HF care in this complex population. ${ }^{40}$

Although the patient's role has not been fully integrated into clinical practice, the advent of health information technology and health care reform have shifted priorities toward consumer driven health care, so that patients are in a primary position to influence health care quality and cost. To improve the effectiveness of chronic HF care, an understanding of the specific difficulties of self-management is necessary in order to apply targeted interventions and effective CDSM support. Experts in this area highlight these gaps in our current CDSM knowledge base: a) understanding characteristics that influence self-management from a multidisciplinary viewpoint, b) integrating biological and psychological perspectives, and c) building on existing research to answer new questions. ${ }^{67}$

Self-management is widely accepted as a central pathway for multidisciplinary CDSM programs and chronic care models; however, successful quality improvement efforts must also focus on helping individuals become more informed about their illness, actively engage in their own care (activation), and improve their skills for selfmanagement. ${ }^{7}$ Most chronic HF therapy and treatments rely on self-management strategies (eg, telehealth technology, electronic patient records, patient education). Thus, CDSM approaches that encourage patients to become active partners (participants) in their care are necessary to improve the impact of self-management on long-term HF outcomes.

CDSM has been viewed as a viable strategy to bridge the gap between the capacity of the individual and the health care system to meet the needs of individuals with chronic disease and effect improved outcomes. Understanding the relationship among patient characteristics, activation, selfmanagement, and the desired outcomes in HF patients is an important next step. Evidence that patient characteristics, activation, and self-management are of consequence to HF outcomes, opens a new path of inquiry for health services researchers and clinicians. Future research in this area is needed to inform health care stakeholders about the patient's critical role in designing, tailoring, and implementing CDSM care plans for chronic HF care.
Achieving national goals and improving outcomes for people with HF will require the implementation of effective CDSM strategies to close identified gaps in chronic HF care. Improving health care quality and mitigating negative HF outcomes will require identifying barriers to self-management so that targeted strategies for CDSM support can be implemented. To date, quality improvement efforts in chronic HF care have concentrated on discharge failures, hospital and provider level performance, and public reporting of core HF indicators to identify and characterize patient risk. To improve the continuum of chronic HF care will require that health care stakeholders place more emphasis on patient-centered characteristics as a means of understanding patient risk and identifying barriers to selfmanagement, so that effective multidisciplinary strategies for CDSM support can be implemented. Understanding the interplay between patient characteristics, self-management, and activation in chronic HF care is not only timely but necessary to achieve the desired long-term outcomes for HF patients and other complex disease populations.

\section{Acknowledgments}

I would like to acknowledge Martha Shively, $\mathrm{PhD}, \mathrm{RN}$ for her ongoing enthusiasm and support for my dissertation topic and for lending her expertise in behavioral research and content.

I am grateful for the involvement of my dissertation chair, Christine Kasper, $\mathrm{PhD}$ for her timeless energy and expert comments on this and other manuscripts over the past several years.

I extend my appreciation to Ben Y Tseng, PhD and Marilynne Tseng, BSN, RN for their editorial comments and revisions in preparing this manuscript.

I would also like to thank Barbara Gray, MA for her eagle eye and editorial expertise.

Funded by the Department of Veterans Affairs, Veterans Health Administration, Health Services Research and Development, project \# 04-252.

\section{Disclosure}

The author declares no conflicts of interest.

\section{References}

1. Hunt SA, Abraham WT, Chin MH, et al. Focused update incorporated into the ACC/AHA 2005 Guidelines for the diagnosis and management of heart failure in adults: A report of the American College of Cardiology Foundation/American Heart Association Task Force on practice guidelines developed in collaboration with the international society for heart and lung transplantation. J Am Coll Cardiol. 2009;53(15): e1-e90. 
2. Lloyd-Jones D, Adams RJ, Brown TM, et al. Executive Summary: heart disease and stroke statistics - 2010 update: a report from the American Heart Association. Circulation. 2010;121(7):948-954.

3. Curtis LH, Greiner MA, Hammill BG, et al. Early and long-term outcomes of heart failure in elderly persons, 2001-2005. Arch Intern Med. 2008;168(22):2481-2488.

4. Dunlay SM, Redfield MM, Weston SA, et al. Hospitalizations after heart failure diagnosis: A community perspective. Am Coll Cardio. 2009;54(18):1695-1702.

5. Jencks AF, Williams MV, Coleman EA. Rehospitalizations among patients in the Medicare Fee-for-Service Program. $N$ Engl $J$ Med. 2009;360(14):1418-1427.

6. Ross JS, Chen J, Lin Z, et al. Recent national trends in readmission rates after heart failure hospitalization. Circ Heart Fail. 2010;3(1): 97-103.

7. Adams K, Corrigan JM, editors. Institute of Medicine. Priority Areas for National Action: Transforming Health Care Quality. Washington, DC: National Academic Press; 2003.

8. Bodenheimer T, Chen E, Bennett HD. Confronting the growing burden of chronic disease: can the US health care workforce do the job? Health Aff (Millwood). 2009;28(1):64074.

9. Sochalski H, Jaarsma T, Krumholz HM, et al. What works in chronic care management: the case of Heart Failure? Health Aff (Millwood). 2009;28(1):179-189.

10. Krumholz HM, Currie PM, Riegel B, et al. Taxonomy for disease management: a scientific statement from the American Heart Association Disease Management Taxonomy Writing Group. Circulation. 2006; 114(13):1432-1445.

11. Center for Disease Control and Prevention. State of aging and health in America report. Washington, DC: US Department of Health and Human Services; 2007.

12. Bodenheimer T. Disease management in the American market. BMJ. 2000;320(7234):563-566.

13. Hoffman C, Rice D, Sung HY. Persons with chronic conditions: their prevalence and cost. JAMA. 1996;276(18):1473-1479.

14. Agency for Healthcare Research and Quality. Patient Self-Management Support Programs: An Evaluation. Final contract report. AHRQ publication No. 08-0011. November 2007. Rockville, MD. http://www. ahrq.gov/qual/ptmgmt/. Accessed December 9, 2010.

15. Lorig KR, Holman HR. Self-management education: history, definition, outcomes, and mechanisms. Ann Behav Med. 2003;23(1):1-7.

16. Barlow J, Wright C, Sheasby J, Turner A, Hainsworth J. Selfmanagement approaches for people with chronic conditions: a review. Patient Educ Couns. 2002;48(2):177-187.

17. Riegel B, Moser DK, Anker SD, et al. State of the science: promoting self-care in persons with heart failure. A scientific statement from the American Heart Association. Circulation. 2009;120(12): $1131-1163$.

18. Fonarow GC, Yancy CW, Heywood JT, et al. Adherence to heart failure quality-of-care indicators in US hospitals: analysis of the ADHERE Registry. Arch Intern Med. 2005;165(13):1469-1477.

19. Cameron J, Worrall-Carter L, Riegel B, Lo SK, Stewart S. Testing a model of patient characteristics, psychological status, and cognitive function as predictors of self-care in persons with chronic heart failure. Heart Lung. 2009;38(5):410-441.

20. Jaarsma T, Abu-Saad HH, Dracup K, Halfens R. Self-care behaviour of patients with heart failure. Scand J Caring Sci. 2000;14(2):112-119.

21. Braunstein JB, Anderson GF, Gerstenblith B, et al. Noncardiac Comorbidity Increases Preventable Hospitalizations and Mortality Among Medicare Beneficiaries With Chronic Heart Failure. J Am Coll Cardiol. 2003;42(7):1226-1233.

22. Rich MW. Heart failure in the oldest patients: the impact of comorbid conditions. Am J Geriatric Cardiol. 2005;14(3):134-141.

23. Kfoury AG, French TK, Horne BD, et al. Incremental survival benefit with adherence to standardized heart failure core measures: a performance evaluation study of 2,958 patients. J Card Fail. 2008; 14(2):103-105.
24. Institute of Medicine of the National Academies, Committee on Redesigning Health Insurance Performance Measures, Payment, and Performance Improvement Programs. Rewarding Provider Performance: Aligning Incentives in Medicare. Washington, DC: National Academy Press, Inc; 2007.

25. Fonarow GC, Corday E; ADHERE Scientific Advisory Committee. Overview of acutely decompensated congestive heart failure (ADHF): a report from the ADHERE registry. Heart Fail Rev. 2004;9(3):179-185.

26. Fonarow GC, Abraham WT, Albert NM, et al. Organized Program to Initiate Lifesaving Treatment in Hospitalized Patients with Heart Failure (OPTIMIZE-HF): rationale and design. Am Heart J. 2004;148(1):43-51.

27. O'Connor CM, Stough WG, Gallup DS, Hasselblad V, Gheorghiade M. Demographics, clinical characteristics, and outcomes of patients hospitalized for decompensated heart failure: observations from the IMPACT-HF registry. $J$ Card Fail. 2005;11(3):200-205.

28. Adams KF Jr, Fonarow GC, Emerman CL, et al. Characteristics and outcomes of patients hospitalized for heart failure in the United States: rationale, design, and preliminary observations from the first 100,000 cases in the Acute Decompensated Heart Failure National Registry (ADHERE). Am Heart J. 2005;149(2):209-216.

29. Kociol RD, Hammill BD, Fonarow GC, et al. Generalizability and longitudinal outcomes of a national heart failure clinical registry: comparison of Acute Decompensated Heart Failure National Registry (ADHERE) and non-ADHERE Medicare beneficiaries. Am Heart $J$. 2010;160(5):885-892.

30. Jha AK, Orav EJ, Epstein AM. Public reporting of discharge planning and rates of readmission. $N$ Engl J Med. 2009;361(27):2637-2645.

31. Zambroski CH, Moser DK, Bhat G, Ziegler C. Impact of symptom prevalence and symptom burden on quality of life in patients with heart failure. Eur J Cardiovasc Nurs. 2005;4(3):198-206.

32. Trupp RJ, Hiestand B, Dodge G, et al. Patient Education. Crit Pathw Cardiol. 2008;7(2):116-121.

33. Moser DK, Doering LV, Chung ML. Vulnerabilities of patients recovering from an exacerbation of chronic heart failure. Am Heart $J$. 2005;150(5):984e 7-984e13.

34. Lemon SC, Olenclzki B, Magner R, et al. The dietary quality of persons with heart failure in NHANES 1999-2006. J Gen Intern Med. 2010; 25(2):135-140.

35. Ambardeckar AV, Fonarow GC, Hernandez AF, et al. Characteristics and in-hospital outcomes for nonadherent patients with heart failure: findings from Get with the Guidelines-Heart Failure (GWTG-HF). Am Heart J. 2009;158(4):644-652.

36. Connelly CE. An empirical study of a model of self-care in chronic illness. Clin Nurse Spec. 1993;7(5):247-253.

37. Chriss PM, Sheposh J, Carlson B, et al. Predictors of successful heart failure self-care maintenance in the first three months after hospitalization. Heart Lung. 2004;33(6):345-353.

38. Rockwell JM, Riegel B. Predictors of self-care in persons with heart failure. Heart Lung. 2001;30(1):18-25.

39. Artinian NT, Magnan M, Sloan M, Large MP. Self-care behaviors among patients with heart failure. Heart Lung. 2002;31(3):161-172.

40. Riegel B, Carlson B. Facilitators and barriers to heart failure self-care. Patient Educ Couns. 2002;46(4):287-295.

41. Riegel B, Vaughn Dickson V, Goldberg LR, Deatrick JA. Factors associated with the development of expertise in heart failure self-care. Nurs Res. 2007;56(4):235-243.

42. Cameron, Worrall-Carter, Page, et al. Self-care behaviors among patients with heart failure. Heart Lung. 2010;31(3):161-172.

43. Richardson LG. Psychosocial issues in patients with congestive heart failure. Prog Cardiovasc Nurs. 2003;18(1):19-27.

44. Sayers SL, Riegel B, Pawlowski S, Coyne JC, Samaha FF. Social support and self-care of patients with heart failure. Ann Behav Med. 2008;35(1):70-79.

45. Hibbard JH, Stockard J, Mahoney ER, Tusler M. Development of the Patient Activation Measure (PAM): conceptualizing and measuring activation in patients and consumers. Health Serv Res. 2004;39(4 part 1): $1005-1026$. 
46. US Department of Health and Human Services, Agency for Healthcare Research and Quality. The Guide to Clinical Preventive Services: 2006 Recommendations of the US Preventive Services Task Force. Washington, DC: US Dept of Health and Human Services; June 2006. AHRQ publication 06-0588.

47. Institute of Medicine's Committee on Quality of Health Care in America (2001). Crossing the Quality Chasm: A New Health System for the 21st Century. Washington, DC: National Press.

48. Hibbard JH. Engaging health care consumers to improve the quality of care. Med Care. 2003;41(1 Suppl):I61-I70.

49. Hibbard J, Mahoney E. Toward a theory of patient and consumer activation. Patient Educ Couns. 2010;78(3):377-381.

50. Hibbard JH, Mahoney ER, Stockard J, Tusler M. Development and testing of a short form of the patient activation measure. Health Serv Res. 2005;40(6 pt 1):1918-1930.

51. Hibbard JH, Mahoney ER, Stock R, Tusler M. Do increases in patient activation result in improved self-management behaviors? Health Serv Res. 2007;42(4):14443-14463.

52. Mosen DM, Schmittdiel J, Hibbard J, Sobel D, Remmers C, Bellows J. Is patient activation associated with outcomes of care for adults with chronic conditions? J Ambul Care Manage. 2007;30(1):21-29.

53. Dixon A, Hibbard J, Tusler M. How do people with different levels of activation self-manage their chronic conditions? Patient. 2009;2(4): 257-268.

54. Hamner JB, Ellison KJ. Predictors of hospital readmission after discharge in patients with congestive heart failure. Heart Lung. 2005; 34(4):231-239.

55. Philbin EF, Dec GG, Jenkins PL, DiSalvo TG. Socioeconomic status as an independent risk factor for hospital readmission for heart failure. Am J Cardiol. 2001;87(12):1367-1371.

56. Setoguchi S, Warner Stevenson L. Hospitalizations in patients with heart failure: who and why. J Am Coll Cardiol. 2009;54(18):1703-1705.

57. Naylor MD, Sochalski JA. Scaling up: bringing the transitional care model into the mainstream. Issue Brief (Commonwealth Fund). 2010 Nov; 103:1-12.
58. Naylor MD, Feldman PH, Keating S, et al. Translating research into practice: transitional care for older adults. J Eval Clin Pract. 2009;15(6): 1164-1170.

59. NewCourtland Center for Transitions and Health, University of Pennsylvania School of Nursing, Philadelphia, PA. The Transitional care model. Published 2008-2009. http://www.transitionalcare.info. Accessed January 15, 2011.

60. American College of Cardiology. Hospital to Home: H2H National Quality Improvement Initiative. Published 2011. http://www.h2hquality. org/Home/tabid/38/Default.aspx. Accessed January 15, 2011.

61. Ditewig JB, Blok H, Havers J, van Veenendaal H. Effectiveness of self-management interventions on mortality, hospital readmissions, chronic heart failure. Patient Educ Couns. 2010;78(3):297-315.

62. Jovicic A, Holroyd-Leduc JM, Straus SE. Effects of self-management intervention on health outcomes of patients with heart failure: a systematic review of randomized controlled trials. BMC Cardiovasc Disord. 2006;6:1-8.

63. Holland R, Battersby I, Harvey E, Lenaghan E, Smith J, Hay L. Systematic review of multidisciplinary interventions in heart failure. Heart Lung. 2005;91(7):899-906.

64. McAlister FA, Stewart S, Ferrua S, McMurray JJ. Multidisciplinary strategies for the management of heart failure patients at high risk for admission: a systematic review of randomized trials. J Am Coll Cardiol. 2004;44(4):810-819.

65. Konstam M, Konstam V. Heart failure disease management: A sustainable energy source for the health care engine. JACC. 2010; 56(5):379-381.

66. Clark AM, Savard LA, Thompson DR. What is the strength of evidence for heart failure disease-management programs? JACC. 2009;54(5): $397-401$.

67. Moser DK, Watkins JF. Conceptualizing self-care in heart failure: a life course model of patient characteristics. J Cardiovasc Nurs. 2008;23(3): 205-218.
Journal of Multidisciplinary Healthcare

\section{Publish your work in this journal}

The Journal of Multidisciplinary Healthcare is an international, peerreviewed open-access journal that aims to represent and publish research in healthcare areas delivered by practitioners of different disciplines. This includes studies and reviews conducted by multidisciplinary teams as well as research which evaluates the results or conduct of such teams or

\section{Dovepress}

healthcare processes in general. The journal covers a wide range of areas and welcomes submission from practitioners at all levels, from all over the world. The manuscript management system is completely online and includes a very quick and fair peer-review system. Visit http://www.dovepress.com/testimonials.php to read real quotes from published authors. 